\title{
Identification and classification of barriers and benefits of requirements traceability in project development
}

\author{
Sávio Rocha Aleixo, Carina Campese * and Janaina Mascarenhas \\ Production Engineering Department, University of Sao Paulo - USP, São Carlos, Brazil. Av. Trabalhador São Carlense, 400, \\ São Carlos - SP - Brazil, 13566-590.
}

World Journal of Advanced Engineering Technology and Sciences, 2021, 04(01), 022-039

Publication history: Received on 29 October 2021; revised on 11 December 2021; accepted on 13 December 2021

Article DOI: https://doi.org/10.30574/wjaets.2021.4.1.0080

\begin{abstract}
Requirements are conditions that a product, service, or process must present and requirements management facilitates this realization. For this, the requirements traceability technique is used for the development of projects and systems and all management of the requirements life cycle. However, the literature recognizes the proven benefits of adherence to the technique, but the plurality of problems inhibits its adherence. Thus, this article aims to identify and classify the barriers and benefits of requirements traceability. For this purpose, it was elaborated a systematic literature review, and for the results' analysis and codification, the MAXQDA software was used. A total of 15 barriers and 15 benefits were identified. It is possible to verify that both in the case of benefits and barriers, there is a cause and effect relationship between them. In other words, barriers such as "Low flexibility and integration of tools" lead to the emergence of other barriers such as "Management inefficiency".
\end{abstract}

Keywords: Requirements traceability; Domino effect; Systematic literature review; Requirements management

\section{Introduction}

For the iteration and control of the stages, the requirements traceability is an essential technique in the project activities. It ensures that both products (software and systems) comply with requirements changes, analyzing the impact of requirements changes, observing each identified requirement, investigating all parts of the project document to find any reference to the identified specific requirement, confirming that all the essential stages of the project development process and the development life cycle [1]-[3].

In addition to providing iteration and control throughout the project, the requirements traceability can generate a variety of benefits: quality that the correct product is being produced correctly; monitoring of the process, product execution and final delivery to the customer, that is, monitoring the process development; audit, certifying that the project team is building the product that the customer expects; analysis of the impact of changes, as it is possible to identify the work products influenced by some change; assessment of changes (in project tasks and work products such as files, documents, products, parts of a product, services, process descriptions, specifications [4]; confidence, fulfillment of project objectives with greater confidence; analysis of objectives, standardizing and determining relationships of objectives leads to further analysis of how objectives are met; transparency with suppliers; accuracy of the product development process in the initial phases; and balance and cost-benefit can associate the requirements to the product components enables the evaluation of the benefit over costs [5].

\footnotetext{
${ }^{*}$ Corresponding author: Carina Campese

Production Engineering Department, University of Sao Paulo - USP, São Carlos, Brazil. Av. Trabalhador São Carlense, 400, São Carlos - SP - Brazil, 13566-590. 
Additionally, it can stimulate competitiveness between companies, once companies that do not adopt traceability have the smallest opportunities in the market, and companies that see the support of traceability and business improvement, provide benefits for the company [6].

Despite these advantages, requirements traceability can be difficult and problematic [1]. Observing the benefits of requirements traceability, recognized in the literature, problems such as costs, which are the main cause for nonadherence and the continuation of traceability [7], high cost of tracking maintenance [8], the informality of the traceability development methods [1], technical problems due to the difficulty of using tools [9], lack of support for the traceability tool [1], limitations regarding the support of tools for traceability management [10], lack of time in the schedule to carry out traceability [1], increased project development time, due to the adoption of traceability, it increases the amount of work of the employees involved and minimal incentives for adoption, making the Developers $\mathrm{s}$ recognize traceability as an optional activity [11].

In addition to the recognized problems, traceability is not noticeable by stakeholders, due to the additional effort it entails and the minimal explicit benefits [11], [12]. In this context, the importance, the plurality of recognized problems, and the benefits of requirements traceability are observed, which motivates the categorization of problems into barriers and makes the benefits more explicit, through this research.

Based on the context presented, this research aims to identify and classify the barriers and benefits of requirements traceability pointed out in the literature, making the benefits more explicit in order to mitigate existing barriers to requirements traceability.

\section{Requirements management}

Requirements are the condition, characteristic, obligation, or capability that a product, service, or process must present [13] and need to demonstrate value and be useful to the interested parties in the product [14]. Requirements are classified into functional (FR) or non-functional requirements (NFR). A FR requirement is an assignment that a system must be able to fulfill [15], in other words, is what the product or system must perform [16]. A NFR requirement depicts the performance functions or characteristics that a solution must meet, such as quality aspects, legal requirements, user needs, budget constraints, organizational policies, reliability, and external factors [17]. Regardless of classification, the requirements need to be managed during the project development cycle and this process is called "requirements management" [18], which is essential in any product or system development process [19].

There is not only one way to apply requirements management, the phases of its process vary a little between authors. However, they can be compared [20]. Regardless of which phases are followed, requirements management is fundamental for product development, as demand, complexity, and product quality increase [21].

Most requirements management processes act as a complement and few processes integrate the other management phases, however, management is essential for visibility and tracking, as it facilitates the change of requirements, simultaneous processes, and collaboration in dynamic organizations. Therefore, it should be considered as a life cycle process and needs to be carried out during the project and not in the initial stages [27].

\subsection{Requirements lifecycle management}

The requirements life cycle begins with the need or requirement of the interested parties, as a requirement, which must be managed until the final approval with the product or service, through the process of: (1) assess changes, (2) approval/consensus, (3) traceability, (4) preservation, and (5) prioritization [28] (Figure 1). Life cycle conceptualization refers to the state or phase that the requirement is submitted to, as it can be in multiple states simultaneously and requirements lifecycle management ensures that the project, stakeholders, and requirements are consistent and the project is carried out [28]. The requirements life cycle is the movement or useful life of a requirement throughout a project, it is managed by assigning a condition or qualifier to the requirement to represent its status at a given specified time [29].

The requirement life cycle management process occurs when a potential requirement, originating from the elicitation and collaboration (capture) process, is evaluated by business analysts and presented for approval or disapproval by interested parties, and subsequent to the approval of the requirement, it is possible to manage it through the recommended tracking, preservation, and prioritization techniques [28]. Likewise, the purpose of requirement life cycle management is to confirm that the stakeholders, project, and requirements are coherent [30]. Thus, it is necessary to add a phase prior to the evaluation (in the model of [28]): elicitation. 


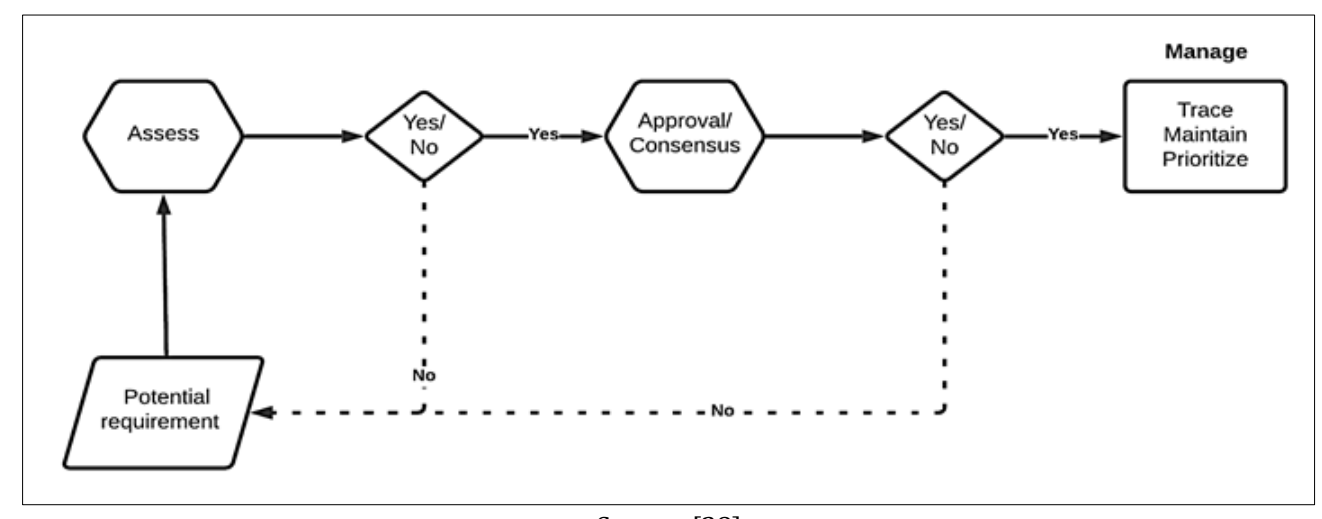

Source: [28]

Figure 1 Requirement Life Cycle Management Process

Then, you arrive at the following process of managing the life cycle of a requirement:

- Elicitation. It is the recognition of the origin of requirements associated with interested parties and needs analysis [31]. However, some requirement functions change due to new information and management verification, with this a function can change even if the requirement does not respond to the change [28].

- Assessment. In the course of the emergence of new needs, an assessment of changes in requirements is carried out and the purpose of the assessment is to analyze the consequences of changes in requirements in the project [28].

- Approval. Obtaining an agreement on the new requirements, changes, communication, discussions, conducting and managing the approval, is under the responsibility of the managers and the approval of the requirements is the agreement between the interested parties so that the activities and design of the project continue [28].

$\circ$ Traceability. It allows the identification and documentation of the origin of each requirement and the relationships with other requirements [28].

- Preservation. Maintain the certainty and aspect of the requirement, to favor its reuse in other projects [28, p.83].

- Prioritization. Ranks requirements in terms of their importance to project stakeholders [28]. The management is not finalized after the requirement is implemented, the project continues to provide value through proper requirements management [30].

In addition to the importance of requirements lifecycle management activities, requirements traceability is also fundamental for the development of projects, acting as a facilitating technique for requirement management and lifecycle. This study is focused on the traceability stage, its benefits and barriers.

\subsection{Requirements traceability}

Studies on the development of tools for requirements traceability appear in the 70s [32], [33], since such traceability began to be required in the standardization process of software and systems development [34]. However, it was only in the 1990s that studies on traceability gained more strength [35], and requirements traceability was defined as the "ability to follow and describe the life of a requirement, from its origins, through its development and specification, to its implementation and use later, in the course of all phases of refinement and iteration at any stage" [1, p.4]. The pioneers' studies [35], [1] presented the problems related to the requirements traceability, namely: lack of a common definition; high cost; tools and inefficient methods adopted by companies; minimal involvement of company employees; difficulty in tracking the origins of the requirement; inadequate specification of requirements; non-perception of problems; efforts to maintain traceability are not rewarded; lack of interest on the part of developers; and optionality by companies.

Even so, in the 2000s, research on the automation of traceability found the persistence of problems associated with tracking activities, while there was an increase in research focusing on automated traceability [36]. The persistence of problems is notable among professionals, who do not understand the concepts, thus presenting inconsistencies in the use of vocabulary. Furthermore, in the 2010s researchers still realize that there is little influence of academic research in organizations, causing poor documentation of requirements and low traceability practice [37], [38]. Even with the recognized problems and benefits, the requirements traceability is still recommended as an essential activity in the project and continues after the verification and validation of the requirements [4], [39] to ensure product performance 
in line with the requirements of different stakeholders and business purpose [30]. Through traceability, the requirements, customer needs (user requirements, business objectives, or market demands) are tracked to understand which requirements will be influenced, if, during or after the project development, the customer's needs change [40].

Figure 2 shows the four types of requirements traceability links, which confirms the stages of the development process, origins and links, which are labels that have the same purpose or similar structure [38] between requirements the origins (customer needs) and between requirements to the components that implement them (work product, artifact) [41]. The link can be of the dependency, refinement, evolution, satisfaction, overlap, conflict, and justification type, it is a link between two tracking artifacts from source to destination, and each tracking link can be followed in two directions, that is, bidirectional and examples of types of tracking links are: "test", "implement" and "replace" [38], [42].

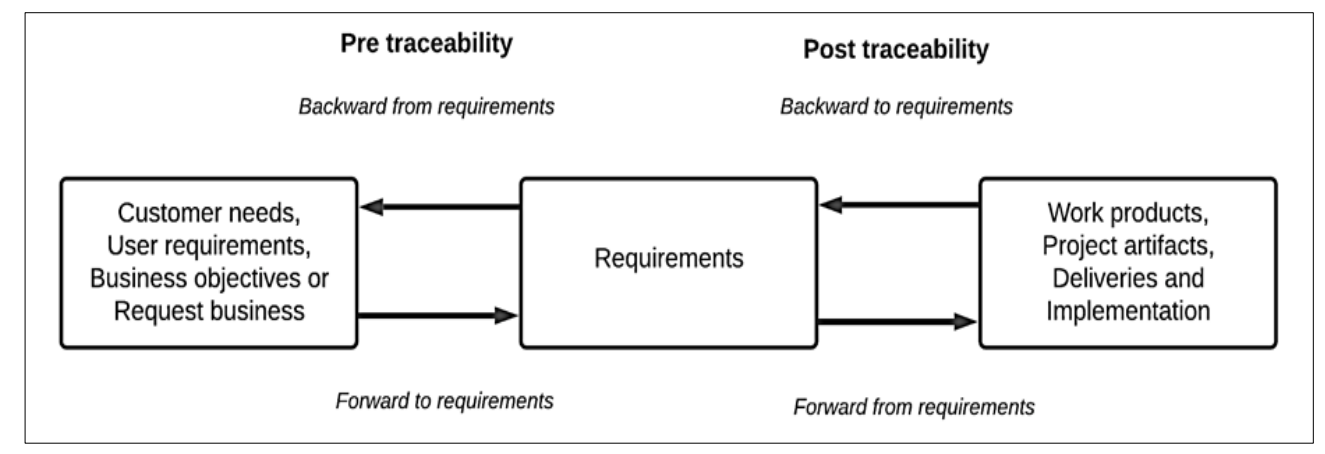

Source: Adapted from [40], [41]

Figure 2 The four types of requirements traceability links

The forward to requirements and backward from requirements tracking are part of the pre-traceability, where the origins of the requirement are documented, justification of the existence of the requirement and stakeholder needs, business objectives or market demands are tracked to the requirements [43], [44]. Forward from requirements and backward to requirements traces are part of post traceability and relate requirements to design, implementation, trace the requirement to system process artifacts, components, and verification cases, where the assignment of team responsibilities and verification from compliance, the impact analysis of a requirement is documented [43].

Several researches to solve the requirements traceability problems are carried out [8] and in the last twenty years, they have studied the requirements traceability challenges faced by professionals [38]. Despite much published empirical research, little research aims to define the state of traceability practice and the challenges faced [10]. A barrier is anything that hinders or prevents the achievement or achievement of something [45] and a benefit is every advantage produced by something, state, action or fruitful result [46]. In addition, a benefit can be a better result and advantages experienced by technology users [47]. According to Regan et al. [9], there is difficulty in collecting information, such as variations in terminology and meaning that can impair the ability to effectively transmit requirements information from customers to designer, however, as a benefit to traceability, it favors communication between the teams in the project to mitigate the difficulties in associating reasons and origins with requirements [48], [49]. Therefore, information on tracking helps to obtain benefits [50], such as the interpretation of customer requirements, which proves what the system performs and what is expected of him/her [51].

Given the above, the literature recognizes the plurality of problems and benefits of requirements traceability, however, there is a need to make the problems categorized into barriers, aiming at a more visible classification and benefits for the recognition of interested parties.

\section{Methodology}

To facilitate research on the identification and categorization of the barriers and benefits of requirements traceability, a systematic literature review (SLR) was elaborated. A SLR is a resource to recognize, examine and interpret important research in an area, research questions, or an event of interest [52].

The process followed for the SLR was based on the model suggested by Conforto et al. [53], and comprises the steps shown in table 1 . The procedure used for each step is detailed in the same table. 
Table 1 The systematic literature review process followed in this work

Step 1: Elaboration of search strings, using logical Boolean search operators.

Strings used:

(1) "requirements traceability" and "requirements tracing"

(2) "traceability requirements" and "project development"

Databases used: Scopus, Engineering Village, Google Scholar and Researchgate

Step 2: Definition of inclusion criteria

The SLR sought to identify the benefits and theoretical and practical problems in requirements traceability. Articles that did not contain such information were excluded during the application of filters.

Step 3: Definition of the search method, tools, and filters

Filter 1: Reading the title, abstract, and keywords

Filter 2: Introduction and conclusion reading

Filter 3: Complete reading

Step 4: Analysis of selected articles

Rereading selected articles and coding them with MAXQDA software support. (1) Barriers to requirements traceability and; (2) Benefits of requirements traceability.

Additionally, in addition to the articles selected from SLR, it was also consulted the BABOK knowledge guides [28] and Business Analysis for Practitioners PMI [29], which complement the literature review from the practical point of view of the topic. For identification and classification of the type of barriers and benefits, codes were determined to be categorized in the MAXQDA software, 1) Barriers for requirements traceability and; 2) Benefits of requirements traceability. The order of categorization of barriers and benefits was based on the number of mentions of the problems and benefits of requirements traceability, in the literature review and final results of the articles identified between the years 1994 and 2020. Table 2 presents the number of articles identified in the scientific databases from the strings.

Table 2 The number of articles identified in the scientific bases about the barriers and benefits of requirements traceability

\begin{tabular}{|c|c|c|c|}
\hline \multirow{2}{*}{$\begin{array}{l}\text { Strings: (1) "requirements traceability" and "requirements } \\
\text { tracing" } \\
\text { (2) "traceability requirements" and "project development" }\end{array}$} & \multicolumn{3}{|c|}{ Scientific bases } \\
\hline & Scopus & Engineering Village & Google Scholar \\
\hline String 1 & 450 & 1105 & 1360 \\
\hline String 2 & 252 & 860 & 190 \\
\hline \multicolumn{4}{|l|}{ Filter 1: Reading the title, abstract and keywords } \\
\hline String 1 & 166 & 46 & 157 \\
\hline String 2 & 153 & 7 & 26 \\
\hline \multicolumn{4}{|l|}{ Filter 2: Introduction and conclusion reading } \\
\hline String 1 & 25 & 14 & 46 \\
\hline String 2 & 46 & 2 & 26 \\
\hline \multicolumn{4}{|l|}{ Filter 3: Full Reading } \\
\hline String 1 & 25 & 14 & - \\
\hline String 2 & 14 & 2 & - \\
\hline Selected articles & 20 & 10 & 8 \\
\hline
\end{tabular}


After the analysis of the 38 selected articles, it was identified that 30 articles address barriers and 33 address the benefits of requirements traceability, according to predefined criteria. From the total number of selected articles, categories for barriers and benefits were established. Table 3 presents the articles that present barriers and benefits to requirements traceability.

Table 3 Articles that address requirements traceability barriers

\begin{tabular}{|c|c|c|c|c|c|}
\hline ID & Year & Country & Business area & Use & Reference \\
\hline 1 & 1994 & UK & Telecommunications & $\begin{array}{l}\text { Communication Solutions and } \\
\text { Services }\end{array}$ & {$[1]$} \\
\hline 2 & 1997 & UK & Software & Software Development & [1] \\
\hline 3 & 1998 & USA & Systems & Systems Development & [54] \\
\hline 4 & 2000 & USA & Software & Software Development & [55] \\
\hline 5 & 2001 & USA and Germany & Software & Software Development & [48] \\
\hline 6 & 2003 & Germany & Automotive & $\begin{array}{ll}\text { Electronic } & \text { Systems } \\
\text { Development } & \\
\end{array}$ & [56] \\
\hline 7 & 2004 & Germany & Multiple Sectors & Tool Development & [57] \\
\hline 8 & 2005 & UK & Software & Software Development & [58] \\
\hline 9 & 2005 & USA & Software & Software Architecture & [59] \\
\hline 10 & 2005 & USA and Austria & Software & Software Development & {$[60]$} \\
\hline 11 & 2005 & Austria & Software & Software Development & [61] \\
\hline 12 & 2006 & UK & Software & $\begin{array}{l}\text { Systems And Software } \\
\text { Development }\end{array}$ & [62] \\
\hline 13 & 2006 & UK & Manufacturing & Electronic Circuits & [6] \\
\hline 14 & 2007 & Netherlands & I.T & $\begin{array}{l}\text { Development Of Information } \\
\text { Systems }\end{array}$ & [11] \\
\hline 15 & 2008 & Italy & Software & Software Development & [63] \\
\hline 16 & 2008 & USA and UK & Construction & Construction Projects & [27] \\
\hline 17 & 2008 & Russia and USA & Telecommunications & Systems Development & {$[8]$} \\
\hline 18 & 2009 & USA & Software & Software Development & [64] \\
\hline 19 & 2012 & Ireland & $\begin{array}{l}\text { Telecommunications } \\
\text { And Software }\end{array}$ & $\begin{array}{l}\text { Systems And Software } \\
\text { Development }\end{array}$ & [9] \\
\hline 20 & 2012 & Sweden & Software & Software Development & [7] \\
\hline 21 & 2013 & Germany & Software & Software Development & [65] \\
\hline 22 & 2014 & Germany and Switzerland & Software & Product-Service System & [66] \\
\hline 23 & 2014 & USA and UK & Construction & Construction Projects & [18] \\
\hline 24 & 2016 & Brazil & Software & Software Development & [67] \\
\hline 26 & 2016 & Brazil & Software & Software Development & [68] \\
\hline 27 & 2018 & Sudan & Software & Software Systems & [69] \\
\hline 28 & 2018 & Australia & Software & Software Development & [70] \\
\hline 29 & 2018 & China & Software & Software Development & [71] \\
\hline 30 & 2020 & Sweden, Germany and Italy & Software & Software Development & {$[10]$} \\
\hline
\end{tabular}

Table 3 presents 30 articles that bring to the debate topics related to requirements management, models, tools, requirements traceability practice, problems faced that inhibit or hinder the use of requirements traceability, acted as sources of research and encouragement for others research in the last twenty years, justifying the authors [8], [38]. In addition to identifying the period in which studies on the problems and barriers to requirements traceability began, it 
is also observed the sectors and areas of use of requirements traceability that most recognized the problems for the use of the technique, namely: 1) Software development; 2) Systems development.

In parallel with the research on requirements traceability problems (Table 3), research on the benefits of requirements traceability became evident (Table 4), making a counterpoint to the problems presented. Additionally, through systematic literature review, it was possible to identify the organizations and areas that most benefit from requirements traceability.

Table 4 Articles that discuss the benefits of requirements traceability

\begin{tabular}{|c|c|c|c|c|c|}
\hline ID & Year & Country & Business area & Use & Reference \\
\hline 1 & 1994 & UK & Telecommunications & $\begin{array}{l}\text { Communication solutions and } \\
\text { services }\end{array}$ & [1] \\
\hline 2 & 1994 & USA & Software & Systems development & [72] \\
\hline 3 & 1998 & USA & Systems & Systems development & [54] \\
\hline 4 & 2000 & UK and Canada & Software & Software development & [73] \\
\hline 5 & 2000 & UK & Software & Software development & [74] \\
\hline 6 & 2001 & USA and Germany & Software & Software development & [48] \\
\hline 7 & 2003 & Germany & Automotive & Electronic systems development & [56] \\
\hline 8 & 2004 & Germany & Systems & Systems development & [19] \\
\hline 9 & 2004 & Germany & Multiple sectors & Tool development & [57] \\
\hline 10 & 2005 & UK & Software & Software development & [58] \\
\hline 11 & 2005 & USA & Software & Software architecture & [59] \\
\hline 12 & 2005 & Austria & Software & Software development & [60] \\
\hline 13 & 2006 & USA & Software & Systems and software development & [62] \\
\hline 14 & 2006 & UK & Manufacturing & Electronic circuits & {$[6]$} \\
\hline 15 & 2007 & Netherlands & I.T & Development of information systems & [11] \\
\hline 16 & 2008 & UK and USA & Civil & Civil projects & [27] \\
\hline 17 & 2008 & Russia and USA & Telecommunication & Systems development & [8] \\
\hline 18 & 2009 & USA & Systems & Systems development & [75] \\
\hline 19 & 2009 & USA & Software & Software development & [64] \\
\hline 20 & 2011 & Spain & Software & Systems development & [76] \\
\hline 21 & 2012 & Sweden & Software & Software development & [7] \\
\hline 22 & 2013 & Germany & Software & Software development & [65] \\
\hline 23 & 2013 & Italy & Software & Software development & [77] \\
\hline 24 & 2014 & $\begin{array}{l}\text { Germany } \\
\text { Switzerland }\end{array}$ & Software & Product Service-System & [66] \\
\hline 25 & 2014 & USA and UK & Civil & Civil projects & [18] \\
\hline 26 & 2016 & Germany & Automotive & Systems development & [78] \\
\hline 27 & 2016 & Brazil & Software & Software development & [68] \\
\hline 28 & 2018 & Sudan & Software & Sistemas de software & [69] \\
\hline 29 & 2018 & Australia & Software & Software development & [70] \\
\hline 30 & 2018 & China & Software & Software development & [71] \\
\hline 31 & 2019 & Finland & Manufacturing & $\begin{array}{l}\text { Elevators, automatic doors, access } \\
\text { systems and services }\end{array}$ & [30] \\
\hline 32 & 2020 & Australia and Indonesia & Software & Software development & [79] \\
\hline 33 & 2020 & $\begin{array}{l}\text { Sweden, Germany and } \\
\text { Italy }\end{array}$ & Software & Software development & [10] \\
\hline
\end{tabular}


After the literature review and content analysis of the identified articles, a categorization of the types of barriers and benefits of requirements traceability was elaborated. In total, 15 barriers and 15 benefits of requirements traceability in project development were categorized according to the recurrence in the literature, between 1994 and 2020.

\section{Results}

In this topic, there are the problems of greater recognition in the literature, through the organizations studied that use the technique of requirements traceability, in the development of projects, categorized in barriers, in order of greatest to least occurrence.

\subsection{Barriers to requirements traceability}

After carrying out the systematic literature review, 15 barriers to the requirements traceability were id entified and classified, as follows: Management inefficiency (B 1); Tools (B 2); Cost (B 3); Insufficiency of methods (B 4); Low benefit perception (B 5); High effort (B 6); Complexity of the technique (B 7); Time Demand (B 8); Low technical support (B 9); Standardization (B 10); Low motivation (B 11); Insufficient communication (B 12); Knowledge insufficiency; (B 13); Insufficient information (B 14) and Element diversity (B 15) (B 15). The column "Barriers to requirements traceability", presents the barrier(s) that are/are influenced by the main barrier (Table 5).

Table 5 Barriers of requirements traceability in project development and quantitative mentions of the barrier

\begin{tabular}{|c|c|c|c|}
\hline ID & $\begin{array}{l}\text { Number of } \\
\text { mentions }\end{array}$ & $\begin{array}{l}\text { Barriers to requirements } \\
\text { traceability. }\end{array}$ & Barriers to influence requirements traceability. \\
\hline B 1 & 138 & Management inefficiency & Element diversity (B 15) \\
\hline B 2 & 84 & Tools & $\begin{array}{l}\text { Management inefficiency (B 1); Time Demand (B 8); Low } \\
\text { technical support (B 9) and Lack of Standardization (B 10) }\end{array}$ \\
\hline B 3 & 57 & Cost & Tools (B 2); High effort (B 6) and Complexity (B 7) \\
\hline B 4 & 50 & Insufficiency of methods & Management inefficiency (B 1) and Cost (B 3) \\
\hline B 5 & 30 & Low benefit perception & $\begin{array}{l}\text { Tools (B 2); Time Demand (B 8) and Insufficient } \\
\text { knowledge (B 13) }\end{array}$ \\
\hline B 6 & 29 & High effort & Low benefit perception (B 5) \\
\hline B 7 & 22 & Complexity of the technique & Tools (B 2) \\
\hline B 8 & 22 & Time Demand & Management inefficiency (B 1) and Low motivation (B 11) \\
\hline B 9 & 16 & Low technical support & $\begin{array}{l}\text { Tools (B 2); Lack of Standardization (B 10); Insufficient } \\
\text { knowledge (B 13) and Element diversity (B 15). }\end{array}$ \\
\hline B 10 & 16 & Lack of Standardization & Tools (B 2) and Elements diversity (B 15) \\
\hline B 11 & 12 & Low Motivation & $\begin{array}{l}\text { Management inefficiency (B 1) and Insufficient knowledge } \\
\text { (B 13) }\end{array}$ \\
\hline B 12 & 12 & $\begin{array}{l}\text { Communication } \\
\text { insufficiency }\end{array}$ & $\begin{array}{l}\text { Management inefficiency (B 1) and Insufficient knowledge } \\
\text { (B 13) }\end{array}$ \\
\hline B 13 & 10 & Insufficient knowledge & $\begin{array}{l}\text { Management inefficiency (B 1); Tools (B 2) and Lack of } \\
\text { Standardization (B 10) }\end{array}$ \\
\hline B 14 & 10 & Insufficient information & Management inefficiency (B 1) and Low motivation (B 11) \\
\hline B 15 & 9 & Element diversity & $\begin{array}{l}\text { Lack of Standardization (B 10) and Insufficient } \\
\text { information (B 14) }\end{array}$ \\
\hline
\end{tabular}

The consequences of the identified barriers and the power of influencing another barrier or barriers are detailed below.

- B 1: Management inefficiency: may inhibit the use of requirements traceability due to strategy limitations [10] and inadequate analysis of traceability [64]. Furthermore, management inefficiency makes it difficult to establish the collection, updating, and continuity of information [9], which can lead to failures in the tracking of non-functional requirements [7]. In this sense, B 1 can influence the "Elements diversity (B 15), the absence of broad requirements traceability, (pre-traceability: business objectives and post-traceability: deliveries and 
implementation [1], [40], making it difficult to identify elements associated with different project objectives [9], [10].

- B 2: Tools: they can hinder the use of requirements traceability, due to inefficiency, technical problems, and limitations regarding traceability [69]. In addition, they usually do not update artifacts and links, causing artifacts that do not have the same pattern [64]. It is observed that this barrier can influence the barriers "Management inefficiency" (B 1), "Time Demand" (B 8), "Low technical support" (B 9) and "Standardization" (B 10). The tools for requirements traceability are inefficient, due to low integration and flexibility [9], limited technical support [48], and lack of uniformity and certification of tools. Furthermore, artifacts and links (links) are not updated in a timely manner by the tools [64].

- B 3: Cost: may inhibit the use of requirements traceability, as it is widely recognized as a costly technique [7], [8], [64], [70], as well as the maintenance, updating of changes and the use of tools for traceability (B 2) causes an increase in project costs [71]. Furthermore, from the point of view of companies, developing their own tools for traceability is still costly [64], and tracking complex requirements (Complexity of the technique, B 7) demands high effort (High effort, B 6), making it very expensive in practice [60]. In this context, it is observed that the B 3 can influence the barriers "Tools" (B 2), "Complexity" (B 7) and "High effort" (B 6) for requirements traceability.

- B 4: Insufficient methods: it can hinder the requirements traceability due to the absence of effective, accurate, and complete methodologies. In addition, it influences the barriers "Management inefficiency" (B 1) and "Cost" (B 3) [64], [70]. Due to the limitations of strategies for managing the requirement traceability, tracking methods become vulnerable to requirements changes [64]. In addition, there is recognition of the absence of economic methods and less costly practices [62].

- B 5: Low benefits perception: it can prevent the requirements traceability due to the absence of perception, misunderstanding, and underestimation of benefits, in addition to not immediately benefiting the requirements traceability [10], [70]. Additionally, the "Low perception of benefits (B 5) influences the barriers "Tools" (B 2), "Time Demand" (B 8) and "Insufficient knowledge" (B 13), as the non-offer of benefits, reduces the use of technologies [71]. In addition, employees spend less time because they are unaware of the benefits [64], so the low perception of benefits makes it difficult to use traceability in project development.

- B 6: High effort: may inhibit the use of traceability, due to the demand for adherence, maintenance, use, and updating. Furthermore, maintaining the requirements traceability requires effort and awareness [65]. Likewise, for the completeness of traceability, the perception of additional efforts are required to improve the technique [9], but it can cause a large volume of data [71]. On the other hand, wasting effort on less important requirements causes unnecessary work overload and consequently influences the "Low benefits perception" (B 5), even when there are no rewards [54].

- B 7: Complexity of the technique: it can make it difficult to use traceability because even with automated approaches there is no reduction in the complexity of the technique [60]. In addition to being a laborious activity that requires the use of tools [68], it influences the barrier "Tools" (B 2), as the tools for requirements traceability are still complex to use [58], [69]. Additionally, there is the recognition of the difficulty in tracking large unstructured documents, overcoming changes in traceability, determining the level of granularity of requirements [71] and ensure traceability in agile environments [68].

- B 8: Time Demand: may discourage the use of traceability because it is a time-consuming activity to perform [71], which requires time to perform and update [64], which can influence on barrier "Low motivation" (B 11). In agile project development environments, it is considered a waste of time and causes administrative overhead [68], in addition, the project duration time and time for completion are considered as obstacles [70], due to the absence of management, which can influence the barrier "Management inefficiency" (B 1) and lead to the nonperformance of requirements traceability.

- B 9: Low technical support: can inhibit the requirements traceability due to the absence of technical support, support, a low collaboration of the parties, and lack of commitment to the project [64]. Furthermore, it can influence the barriers: "Tools" (B 2); "Standardization" (B 10); "Insufficient knowledge" (B 13); and "Diversity of elements" (B 15). In this sense, there is recognition of the insufficiency of technical support for tools and management [65], which makes traceability difficult, even if the tracking links are captured using the tool [10]. Additionally, regulatory entities provide low support in guiding how to carry out the requirements traceability and there is still a lack of a knowledge guide, materials, and visual resources for teaching [9], [62]. It is also observed that inadequate technical support makes it difficult to track non-functional requirements and change impact analysis [59], and there is also insufficient support due to different points of view in the project [64].

- B 10: Lack of Standardization: it can make it difficult to use the requirements traceability technique in project development due to the lack of certification and uniformity of traceability tools [8], [62]. However, standardsetting entities require the practice of requirements traceability [60], in addition, sponsors, management, and experienced users want only to comply with standards and not really care about the standards results [7], [64], 
[70]. In this sense, it is observed B 10 can influence the barriers "Tools" (B 2) and "Diversity of elements" (B 15).

- B 11: Low motivation: can inhibit the requirements traceability in project development, as there is a lack of incentive [7] and motivation to traditional teams [1] and agile by organizational cultures [68]. On the other hand, by not knowing the benefits, there is a lack of interest from the Developers and motivation for the teams, causing a lack of motivation to use the requirements traceability [68]. It is observed that this benefit can influence the barriers "Management inefficiency" (B 1) and "Insufficient knowledge" (B 13).

- B 12: Insufficient communication: resulting from the lack of communication between employees [9], an insufficient communication can hinder the requirements traceability, as the lack of communication about traceability causes project failures and limits advances [1]. What can influence the barriers "Insufficient knowledge" (B 13) and "Inefficiency of management" (B 1) about process development, as companies still provide little return to researchers [62], which can hinder technical advances and delimit the practice [1]. Additionally, there is still communication difficulty due to the time zone of the distributed teams and the language of the collaborators, causing word divergences [10].

- B 13: Insufficient knowledge: it can make requirements traceability difficult due to the challenge of understanding traceability [7], [11], standardizations, and tracking problems [62]. Additionally, the lack of understanding of errors, awareness, and management, leads to a little definition of how to do it, which causes wide variation in the performance of traceability [8]. Furthermore, the lack of knowledge about traceability discourages companies from developing tools [64]. However, there is recognition of the requirement of study and discipline for adherence and decision-making for traceability [11]. It is observed that the benefit G 13 can influence the barriers "management inefficiency (B 1)", "Tools (B 2)" and "Lack of Standardization (B 10)".

- B 14: Insufficient information: it can prevent the requirements traceability in project development, as the lack of information discourages teams [68] causing the inability to work and locate the requirements [7]. The lack of information about the concept of requirements traceability and objectives consequently discourages the use of the technique [1], [63]. It is also noteworthy that both the lack of transfer information and outdated information cause the minimum transfer of information [1], in addition, information can be forgotten and lost over time [68]. In this context, it is observed that B 14 can influence "Management inefficiency" (B 1) and "Low motivation" (B 11).

- B 15: Elements diversity: may prevent the use of requirements traceability in project development, due to large amounts of methodologies, models, artifacts to trace, incentives and stakeholders working together [9], [48]. Additionally, there is still the challenge of introducing practices in large companies due to a large number of different development environments, diversity of standards [62], and size of the types of projects and products [8]. Moreover, the diversity of information omits defaults [1]. In this sense, it is observed that the barrier "Elements diversity (B 15)" can influence the barriers "Lack of Standardization (B 10)" and "Insufficient information (B 14)".

It is concluded that all 15 barriers to requirements traceability can influence some barrier or more barriers (Table 4), in addition, it is observed that the five barriers that most influence other barriers are: A) "Tools (B 2)"; B) Low technical support (B 9); C) Cost (B 3); and D) "Low benefits perception (B 5)". It is recommended that these five barriers be mitigated to avoid influencing in other barriers.

\subsection{Benefits of requirements traceability}

Parallel to the identification of barriers, 15 benefits of requirements traceability were identified and classified in the same way. According to the number of mentions of benefits (In this work, the word benefit is abbreviated by G (from the word "gain"), as a measure of differentiation from the abbreviation of the word "barrier".) related to the use of the technique, the following are characterized: Management support (G 1); Information (G 2); Quality (G 3); Comprehension (G 4); Customer satisfaction (G 5); Knowledge Generation (G 6); Identification of requirements (G 7); Impact analysis (G 8); Understanding the requirements (G 9); Identification of influences (G 10); Analysis of changes (G 11); Change identification (Tracking changes) (G 12); Agility (G 13); Error analysis (G 14); and Assessment of the requirement (G 15), (Table 6). Next, each identified benefit, respective effects, the occurrence of other benefits, and the power to mitigate barriers are discussed. 
Table 6 Benefits (gains) of requirements traceability and realized benefits

\begin{tabular}{|c|c|c|c|}
\hline ID & $\begin{array}{l}\text { Number } \\
\text { of } \\
\text { mentions }\end{array}$ & $\begin{array}{l}\text { Requirements } \\
\text { Traceability Benefit } \\
\text { Category }\end{array}$ & Benefits that can occur with requirements traceability \\
\hline G 1 & 17 & Management support & $\begin{array}{l}\text { Information (G 2); Quality (G 3); Knowledge Generation (G 6); } \\
\text { Identification of requirements (G 7); and Understanding the } \\
\text { requirements ( } G \text { 9). }\end{array}$ \\
\hline G 2 & 13 & Information & $\begin{array}{l}\text { Knowledge Generation (G 6); Identification of requirements (G 7); } \\
\text { and Identification of changes (Tracking changes) (G 12). }\end{array}$ \\
\hline G 3 & 10 & Quality & Management support (G 1) and Information (G 2) \\
\hline G 4 & 10 & Comprehension & 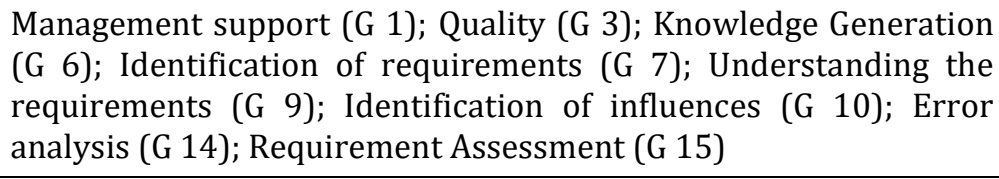 \\
\hline G 5 & 9 & Customer satisfaction & Knowledge Generation (G 6); Requirements identification (G 7) \\
\hline G 6 & 6 & Knowledge generation & $\begin{array}{l}\text { Management support (G 1); Comprehension (G 4); Impact analysis } \\
\text { (G 8); Error analysis ( } \mathrm{G} 14 \text { ) }\end{array}$ \\
\hline G 7 & 6 & $\begin{array}{l}\text { Requirements } \\
\text { identification }\end{array}$ & Knowledge Generation (G 6) \\
\hline G 8 & 6 & Impact analysis & $\begin{array}{l}\text { Analysis of changes (G 11); Change Identification (Tracking } \\
\text { Changes) (G 12) and Agility (G 13) }\end{array}$ \\
\hline G 9 & 5 & $\begin{array}{l}\text { Understanding } \\
\text { requirements }\end{array}$ & Requirements identification (G 7) and Knowledge Generation (G 6) \\
\hline G 10 & 5 & $\begin{array}{l}\text { Identification } \\
\text { influences }\end{array}$ & Identification of requirements (G 7) \\
\hline G 11 & 5 & Change analysis & 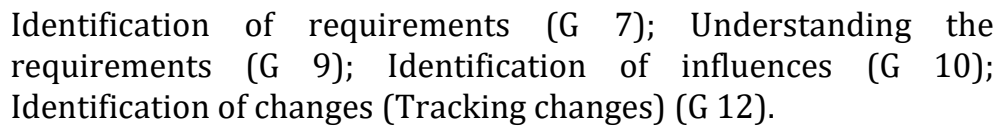 \\
\hline G 12 & 5 & $\begin{array}{l}\text { Identification of } \\
\text { Changes (Tracking } \\
\text { Changes) }\end{array}$ & $\begin{array}{l}\text { Management support" (G 1); "Information" (G 2); "Impact analysis" } \\
\text { (G 8); "Identification of influences" (G 10); “Analysis of changes" (G } \\
\text { 11); "Agility" (G 13), and "Requirement Assessment" (G 15) }\end{array}$ \\
\hline G 13 & 4 & Agility & $\begin{array}{l}\text { Quality (G 3); Understanding (G 4); Knowledge Generation (G 6); } \\
\text { Understanding the requirements (G 9); Analysis of changes ( } G 11 \text { ) }\end{array}$ \\
\hline G 14 & 4 & Error analysis & $\begin{array}{l}\text { Understanding (G 4); Knowledge Generation (G 6); Identification of } \\
\text { influences (G 10) }\end{array}$ \\
\hline G 15 & 4 & $\begin{array}{l}\text { Requirement } \\
\text { Assessment }\end{array}$ & 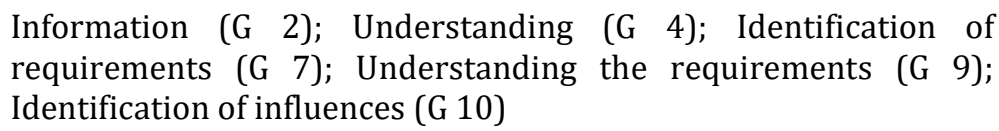 \\
\hline
\end{tabular}

- G 1: Management support: It is recognized as the greatest benefit of requirements traceability and can help manage change and project costs [72], in addition to facilitating requirements and project management in monitoring development [27], enabling effective project control [6], [58]. Besides, it provides support for the management of compliance verification of complex projects and software [66], measures the development of a product [58], and measures the requirements used, completed and in use in the project [7]. It is observed that the benefit "Management support" (G 1) can generate other benefits such as: "Information" (G 2) through control, "Quality" (G 3) compliance verification, "Generation of Knowledge" (G 6), "Identification of requirements" (G 7) and "Understanding the requirements" (G 9), in addition to being able to help mitigate the Cost barrier (B 3). 
- G 2: Information: Through the requirements traceability technique, it can provide important information for making changes [68], where it presents in detail the project information, origin, importance, how the requirement was tested and implemented in the project, consequently assisting in the development of the project [6]. Justifying Blaauboer et al. [11], the development of requirements traceability offers more information. It is observed that the benefit of "Information" (G 2) may influence the occurrence of other benefits such as: "Generation of Knowledge" (G 6), "Requirements identification" (G 7), and "Identification of changes" ( $G$ 12). Additionally, the benefit of "Information (G 2)" can help to mitigate the barriers "Management inefficiency" (B 1), which facilitates the management of requirements by collecting information [48], mitigating the "Insufficient knowledge" (B 13) and "Insufficient information" (B 14) on project details and changes.

- G 3: Quality: The application of requirements traceability produces high-quality products [6], due to the influence of information, which proposes an improvement in product quality [8], readability, of the system and project [76]. Consequently, providing quality as a benefit, in addition, the requirements traceability used, as support to quality management with the combination of Six Sigma, can lead to an improvement in the project schedule, manufacturing process [6], quality system and software maintenance [78]. It is observed that the benefit of "Quality" (G 3) can influence the occurrence of other benefits such as "Management support" (G 1) and Information (G 2). Additionally, the "Quality (G 3)" benefit can reduce "Insufficient information (B 14)" through the information provided by the traceability process.

- G 4: Comprehension: Through requirements traceability, the technique can provide Comprehension as a benefit, where traceability facilitates the understanding of the project, reading of documentations, and verification of requirements [48], in addition to providing process improvement and under what conditions did the problems occur or not [6]. Also, understanding enables the understanding of problems, the relationships between requirements, the importance for problem-solving, requirements evolution [48], and understanding of the system [71]. It is observed that the benefit of "Comprehension" (G 4) traceability can influence the occurrence of other benefits, such as: "Management support" (G 1), "Quality" (G 3), "Knowledge Generation" (G 6), "Requirements identification" (G 7), "Understanding requirements" (G 9), "Influence identification" (G 10), "Error analysis" (G 14), and "Requirement assessment" (G 15). Additionally, it is observed that the benefit "Comprehension" (G 4) can mitigate the barriers "Complexity of the technique (B 7)", "Low technical support (B 9)", and "Insufficient knowledge" (B 13). Furthermore, the problems can guide the understanding of the requirements traceability challenges [70]. The benefits brought about by "Understanding" (G 4) can still generate other benefits to mitigate other existing barriers. It is concluded that "Understanding (G 4)" is the benefit that can further encourage the occurrence of other benefits.

- G 5: Customer satisfaction: The benefit Customer satisfaction, through the use of the requirements traceability technique, can increase customer satisfaction and trust, through cost control and guarantee of obtaining the desired product by the customer [60], [72]. Furthermore, it proves to the customer that the system meets the needs and satisfaction of requirements [80]. Consequently, it is observed that the benefit "Customer satisfaction" (G 5) can encourage the occurrence of the benefits "Knowledge Generation" (G 6) and "Identification of requirements" (B 7) and, additionally, can mitigate barriers: "Cost" (B 3), "Low technical support" (B 9), "Insufficient knowledge" (B 13), and "Insufficient information" (B 14).

- G 6: Knowledge Generation: can be acquired with the use of requirements traceability, which enables the creation of knowledge [48]. Through traceability, knowledge-sharing benefits project team members for learning the use of tools, methodologies, and techniques, consequently increasing the value of the project [54]. Additionally, the preservation of knowledge of the project [76], allows the recognition of manufacturing errors and under which conditions the errors occurred [6]. In this sense, the PMBoK guide [81] can help through knowledge management, ensuring the experiences of the project team and other parties are used before, during, or after the project. It is visibly explicit that the benefit "Generation of Knowledge (G 6)" can generate other benefits such as Management support (G 1), Understanding (G 4); Impact analysis (G 8); and Error analysis (G 14). In addition, it can mitigate barriers such as: "Tools (B 2)", "Low benefits perception (B 5)", "Low technical support (B 9)", "Complexity (B 7)" and "Insufficient knowledge (B 13)", through the creation and sharing of knowledge throughout the life cycle of the project aimed at the teams [48].

- G 7: Requirements identification: the benefit of requirements identification helps to recognize conflicting requirements [60], derivatives, and derived requirements that satisfy the originals [48], in addition to identifying the origin of requirements through documents [6], people and/or groups of people [7]. In addition, the identification of requirements is achieved through verification [68]. It is observed that the benefit "Identification of requirements" (G 7) can influence the generation of the "Knowledge Generation" benefit (G 6) and at the same time can mitigate barriers, "Low technical support (B 9)", "Insufficient of knowledge (B 13)" and "Insufficient information (B 14)" due to the recognition of discordant requirements and origin [60].

- G 8: Impact analysis: through requirements traceability, it can help ensure an impact analysis of the change [82] and what will affect the product and work products [7] in addition to supporting, the analysis of the impact of changes is achieved through verification [68]. Besides, the "Impact analysis" (G 8) can influence the 
occurrence of benefits such as "Analysis of changes" (G 11), "Agility" (G 13), and "Identification of changes" (G 12). Additionally, the benefit of "Impact analysis" (G 8) can mitigate the barriers "Management inefficiency (B 1)" through the support of the analysis and "Insufficient knowledge" (B 13), mitigated by the knowledge generated from the analysis of impact.

- G 9: Understanding the requirements: through the requirements traceability, it can help to understand the importance and evolution of requirements [48], [64], to interested parties to understand how their wishes are considered [74], in addition to facilitating the developer to understand the relationships between the requirements, the support to the requirements traceability tool does not -functional, helps to understand the technique and requirements [59]. It is observed that the benefit "Understanding the requirements" (G 9), can enable the benefits "Identification of requirements" (G 7) and "Knowledge Generation" (G 6). In addition, it can mitigate the barriers "Tools (B 2)", "Low technical support (B 9)", "Complexity of the technique (B 7)" and "Insufficient knowledge (B 13)".

- G 10: Identification of influences: through traceability, it can allow the identification of what was influenced in the project [27] and how the errors are related [6], in addition to tracking requirements, artifacts, elements, work products [8] that can be influenced by design changes [27]. The benefit "Identification of influences" (G 10) can enable the benefit of "Identification of requirements" (G 7) through the information and can additionally mitigate the barriers "Insufficient knowledge (B 13)" and "Insufficient information (B 14)".

- G 11: Change analysis: can provide and facilitate the impact analysis of requirements changes [60], [78]. Additionally, it also enables, through verification, the investigation of the effects of changes [68] and the control of the effects of changes in the product requirements [77], in addition to understanding under what conditions the changes occurred in the manufacturing process [6] and ensure the analysis of the impact of changes [70]. In this sense, it is observed that the benefit "Analysis of changes" (G 11) can influence the occurrence of benefits such as "Identification of requirements" (G 7), "Understanding of requirements" (G 9), "Identification of influences" (G 10) and "Identification of changes" (G 12), which is related to the same benefit. Likewise, the "Analysis of changes" (G 11) can mitigate the barrier "Low technical support (B 9), through the actions provided by it.

- G 12: Identification of changes (Tracking changes): through the requirements traceability, it can facilitate and identify when changes occurred in the project and what changed in change management [6], [58]. In addition, it provides the identification of work products influenced by changes [8], the impact of changes efficiently, assessment of cost, and time implications [69], therefore essential to manage change [72]. In this sense, it is observed that this benefit can influence the occurrence of more benefits such as "Management support (G 1), "Information (G 2)", "Analysis of impact" (G 8), "Influence identification" (G 10); "Change analysis (G 11), "Agility" (G 13) and "Requirement assessment" (G 15). Additionally, "Change Identification (G 12)" can mitigate the barriers "Cost (B 3) and "Time demand (B 8)" by evaluating the consequences of project costs and time in the course of requirements traceability.

- G 13 Agility: it is the benefit obtained through the requirements traceability, as it makes Analysts agile, understandable, and responsible for more easily confirming whether the requirement met the need [48] with traceability [30]. Additionally, it makes it possible to streamline the schedule [72], through knowledge of the testing procedures, which need to be done to verify the change, maintenance, and solutions [78], which improves the quality of the software, positively influencing the product [65], in addition to providing agility in the analysis of the cause of impact of the requirement change [8]. It is clear that this benefit can lead to other benefits such as "Quality" (G 3), "Understanding" (G 4), "Generation of Knowledge" (G 6), "Understanding requirements" (G 9) and "Analysis of changes" (G 11). In addition, agility can mitigate the barriers "High effort" (B 6), "Time demand" (B 8) and "Insufficient knowledge" (B 13), by reducing the effort caused by identifying exact solutions, understanding to confirm more confidently that the requirement met the demand, it also makes it possible to streamline the schedule through knowledge.

- G 14: Error analysis: through traceability, it can provide an analysis of structured and organized errors in the project and product [78], in addition to errors occurring in the project, root cause analysis, and derivation [7]. Additionally, it provides an understanding of how errors are related to the manufacturing batch and where it operates [6] and changes requirements when errors are presented [48]. Likewise, this benefit can influence the occurrence of other benefits such as "Understanding" (G 4), "Generation of Knowledge" (G 6), and "Influences identification" (G 9), in addition to being able to mitigate the barriers "Insufficient knowledge" (B 13) and "Low technical support" (B 9), through a structure of errors in the project, cause and effect analysis of errors in the project, product, and analysis of the impact of requirements changes.

- G 15: Requirement Assessment: by means of requirements traceability, it allows evaluating the completeness and consistency of the requirements [79]checking if the requirement is associated with an objective, priority, and author [8]. Furthermore, it provides an alert identifying conflicting, mandatory requirements and ensures that the requirement is assessed for change and the effects of the change [7], [78]. It is observed that this benefit can influence the occurrence of other benefits such as "Information" ( $G$ 2), "Understanding" (G 4), 
"Requirements identification" (G 7), "Understanding requirements" (G 9) and the "Influence identification" (G 10). Additionally, the same benefit can mitigate the barriers "Insufficient knowledge" (B 13) and "Insufficient information" (B 14) that can be mitigated through the information made possible by the assessment of the requirement during the traceability of the requirements.

It is observed that the problems of the technique become categorized into barriers and more explicit, as well as its benefits, in addition, the benefits can influence the occurrence of other benefits such as "Understanding" (G 4) and "Identification of changes" (Track changes) (G 12). Likewise, given the exposure of the benefits of requirements traceability and the same benefits influence the possibility of occurrence of other benefits and can mitigate existing barriers (Table 7).

Table 7 Benefits (gains) of requirements traceability that can mitigate barriers

\begin{tabular}{|l|l|l|}
\hline ID & $\begin{array}{l}\text { Benefits of requirements } \\
\text { traceability }\end{array}$ & Barriers to the requirements traceability that can be mitigated \\
\hline G 1 & Management support & Cost (B 3) \\
\hline G 2 & Information & $\begin{array}{l}\text { Management inefficiency (B 1); Insufficient knowledge (B 13) and Insufficient } \\
\text { information (B 14) }\end{array}$ \\
\hline G 3 & Quality & Insufficient information (B 14) \\
\hline G 4 & Comprehension & $\begin{array}{l}\text { Complexity of the technique (B 7); Low technical support (B 9) and } \\
\text { Insufficient knowledge (B 13) }\end{array}$ \\
\hline G 5 & Customer satisfaction & $\begin{array}{l}\text { Cost (B 3); Low technical support (B 9); Insufficient knowledge (B 13) and } \\
\text { Insufficient information (B 14) }\end{array}$ \\
\hline G 6 & Knowledge generation & $\begin{array}{l}\text { Tools (B 2); Low perception of benefits (B 5); Low technical support (B 9); } \\
\text { Complexity of the technique (B 7) and Insufficient knowledge (B 13) }\end{array}$ \\
\hline G 7 & $\begin{array}{l}\text { Requirements } \\
\text { identification }\end{array}$ & $\begin{array}{l}\text { Low technical support (B 9); Insufficient knowledge (B 13) and Insufficient } \\
\text { information (B 14) }\end{array}$ \\
\hline G 8 & Impact analysis & Management inefficiency (B 1) and Insufficient knowledge (B 13) \\
\hline G 9 & $\begin{array}{l}\text { Understanding } \\
\text { requirements }\end{array}$ & $\begin{array}{l}\text { Tools (B 2); Complexity of the technique (B 7); Low technical support (B 9) } \\
\text { and Insufficient knowledge (B 13). }\end{array}$ \\
\hline G 10 & Identification of influences & Insufficient knowledge (B 13) and Insufficient information (B 14). \\
\hline G 11 & Change analysis & Low technical support (B 9) \\
\hline G 12 & $\begin{array}{l}\text { Identification of Changes } \\
\text { (Tracking Changes) }\end{array}$ & Cost (B 3) and Time Demand (B 8) \\
\hline G 13 & Agility & High effort (B 6); Time Demand (B 8) and Insufficient knowledge (B 13) \\
\hline G 14 & Error analysis & Low technical support (B 9) and Insufficient knowledge (B 13) \\
\hline G 15 & Requirement Assessment & Insufficient knowledge (B 13) and Insufficient information (B 14). \\
\hline
\end{tabular}

\section{Conclusion}

This work identified 15 barriers and 15 benefits of requirements traceability in project development. The research contributed to 1) Identification and categorization of the barriers and benefits of requirements traceability; 2) Identification of barriers caused by other(s) barrier(s); 3) Identification of benefits generated from another (s) benefit $(\mathrm{s})$; 4) Identification of benefits from the requirements traceability that can mitigate barriers. During research through scientific bases and readings, the authors observed that requirements traceability derives from the area of software engineering and that the field of requirements is broad about management, that is, requirements traceability involves requirements engineering, requirements development, requirements management, and requirement life cycle.

Regarding the barriers and benefits of requirements traceability, a technique associated with requirements management and requirements life cycle [28], the literature recognizes the plurality of problems for realization and the benefits are minimally explicit, however, aiming at a further clarification on what the problems are and answers to the research gaps, a structure is presented with the classification of the 15 barriers and 15 benefits of the traceability of the 
most evident requirements. Additionally, it is observed that both the barriers and the benefits of requirements traceability influence the occurrence of other barriers and benefits, in a "domino effect". That is, the requirements traceability barriers can influence the occurrence of other barriers and benefits can generate other benefits, yet some benefits can mitigate the identified barriers.

Another relevant issue that was observed is the companies that did not realize the benefits that cause other benefits, implicitly, from the use of the requirements traceability technique. It is possible to achieve benefits and these can influence the occurrence of others that the company does not recognize. In this sense, it is recommended that employees be advised on the existence of benefits, combined with the management of benefits and the use of a process for it, which can enable better results, combine benefit plans, and identify the dependencies between individual projects and projects that claim the same benefits [84].

Future work may address how requirements traceability management is performed and monitored in companies, and how the benefits and barriers of this action are seen in practice. It is also suggested to carry out studies on an implicit generation of benefits, and the relationships of barriers that cause a "domino effect", measuring the time to carry out the requirements traceability, barriers, and benefits of requirements traceability on tangible products and a structure with pre-defined motivations for companies to use the requirements traceability in project development.

\section{Compliance with ethical standards}

\section{Acknowledgments}

The authors cordially thank the Coordination of Improvement of Higher Education Personnel (CAPES) for supporting this research.

\section{Disclosure of conflict of interest}

The authors declares that there is no conflict of interest in their research study.

\section{References}

[1] OCZ Gotel, ACW. Finkelstein, "An analysis of the requirements traceability problem," Proc. Int. Conf. Requir. Eng. 1994; 94-101.

[2] F Nilsson. Introduction to Requirements Engineering REBOK Requirements Engineering Body Of Knowledge. 1.0. 2013.

[3] GO'Regan. Concise Guide to Software Engineering: from fundamentals to application methods. Gewerbestrasse, Switzerland: Springer. 2017.

[4] CMMI, CMMI@ for Development, Version 1.3. Software Engineering Institute. 2010.

[5] E Hull, K Jackson, J Dick. Requeriments engineering, 3rd ed. London: Springer. 2010.

[6] M Ford, JD Triggs. "Traceability Requirements in Electronics Assembly," in Intelligent Production Machines and Systems. 2006; 656-662.

[7] R Torkar, T Gorschek, R Feldt, M Svahnberg, UA Raja, K Kamran. "Requirements traceability: A systematic review and industry case study," Int. J. Softw. Eng. Knowl. Eng. 2012; 22(3): 385-433.

[8] V Kirova, N Kirby, D Kothari, G Childress. "Effective requirements traceability: models, tools, and practices," Bell Labs Tech. J. 2008; 12(4): 143-158.

[9] G Regan, F McCaffery, K McDaid, D Flood. "The barriers to traceability and their potential solutions: Towards a reference framework," in Proceedings - 38th EUROMICRO Conference on Software Engineering and Advanced Applications, SEAA. 2012; 319-322.

[10] R Wohlrab, E Knauss, JP Steghöfer, S Maro, A Anjorin, P Pelliccione. "Collaborative traceability management: a multiple case study from the perspectives of organization, process, and culture," Requir. Eng. 2020; 25(1): 2145.

[11] F Blaauboer, K Sikkel, MN Aydin. "Deciding to adopt requirements traceability in practice," in International Conference on Advanced Information Systems Engineering. 2007; 294-308. 
[12] P. Rempel and P. Mäder, "Preventing defects: The impact of requirements traceability completeness on software quality," IEEE Trans. Softw. Eng. 2017; 43(8): 777-797.

[13] F Flores, M Mora, F Alvarez, R O'Connor, J Macias-Luévano. "Requirements engineering: A review of processes and techniques," in Handbook of Research on Modern Systems Analysis and Design Technologies and Applications. 2009; 90-104.

[14] H Rozenfeld et al., Gestão de Projetos em Desenvolvimento de Produtos. São Paulo: Saraiva. 2006.

[15] L Chung, BA Nixon, E Yu. "Dealing with change: An approach using non-functional requirements," Requir. Eng. 1996; 1(4): 238-260.

[16] P Shankar, B. Morkos, and J. D. Summers, "A hierarchical modeling scheme with non functional requirements," in Proceedings of the ASME Design Engineering Technical Conference, 2010, 3, PARTS A AND B. 283-295.

[17] I Sommerville, Engenharia de software, 8th ed. São Paulo: Pearson Addison-Wesley. 2007.

[18] AK Jallow, P Demian, AN Baldwin, C Anumba. "An empirical study of the complexity of requirements management in construction projects," Eng. Constr. Archit. Manag. 2014; 21(5): 505-531, ,

[19] H Halbleib, “Requirements management," Inf. Syst. Manag. 2004; 21(1): 8-14.

[20] C Campese. "Proposta de um framework para aplicação de UCD (User-Centred Design) para pequenas empresas desenvolvedoras de produtos eletromédicos," Universidade de São Paulo. 2019.

[21] ZY Chen, Y Zeng. "Classification of product requirements based on product environment," Concurr. Eng. Res. Appl. 2006; 14(3): 219-230.

[22] J Jiao, MM Tseng. "A requirement management database system for product definition," Integr. Manuf. Syst. 1999; 10: $146-154$.

[23] P Carlshamre, B Regnell. "Requirements lifecycle management and release planning in $\backslash$ nmarket-driven requirements engineering processes," in 11th International Workshop on Database and Expert Systems Applications. September 2000; 961-965.

[24] J Jiao, CH Chen. "Customer requirement management in product development: A review of research issues," Concurr. Eng. Res. Appl. 2006; 14(3): 173-185, ,

[25] R. S. Pressman, Software Engineering. A practitioner's approach, 7th ed. New York: McGraw-Hill. 2010.

[26] M. Chemuturi, Requirements Engineering and Management for Software Development Projects. New York: Springer. 2013.

[27] AK Jallow, P Demian, A Baldwin, C Anumba. "Life Cycle Approach To Requirements Information Management in Construction Projects : State-of-the-Art," in Proceedings of 24th Annual Conference of Association of Researchers in Construction Management ARCOM. 2008.

[28] IIBA, BABOK: a guide to the business analysis body of knowledge, v3 ed. 2015.

[29] Project Management Institute (PMI), Business Analysis for Practitioners: A Practice Guide. GlobalStandard. 2015.

[30] N Dehghani. “Defining Requirements Management Process for Product Development Projects," Helsinki Metropolia University of Applied Sciences. 2019.

[31] M. Peruzzini, E. Marilungo, and M. Germani, "Structured requirements elicitation for product-service system," Int. J. Agil. Syst. Manag. 2015; 8: 3-4, 189-218.

[32] M Dorfman RF Flynn. “Arts-an automated requirements traceability system,” J. Syst. Softw. 1984; 4(1): 63-74.

[33] RA Pierce. “A Requirements Tracing Tool,” Proc. Softw. Qual. Assur. Work. Funct. Perform. 1978; 53-60.

[34] M Dorfman, RH Thayer. "Standards, Guidelines, and Examples on System and Software Requirements Engineering," IEEE Comput. Soc. Press Tutor. 1990.

[35] B Ramesh, M Edwards. "Issues in the development of a requirements traceability model," Proc. IEEE Int. Conf. Requir. Eng. 1993; 256-259.

[36] J Cleland-Huang, R Settimi, E Romanova, B Berenbach, S Clark. "Best practices for automated traceability," Computer (Long. Beach. Calif). 2007; 40(6): 27-36. 
[37] P Mäder, O Gotel, I Philippow. "Motivation matters in the traceability trenches," Proc. IEEE Int. Conf. Requir. Eng. 2009; 143-148.

[38] J Cleland-Huang, O Gotel, A Zisman, Software and Systems Traceability. London: Springer. 2012.

[39] IEEE Standards Board \& Institute of Electrical and Electronics Engineers, "IEEE trial-use standard for application and management of the systems engineering process." Institute of Electrical Electronics Engineers, New York. 1998.

[40] K Wiegers, J Beatty. Software Requirements. Best practices, 3rd ed. Microsoft Press. 2013.

[41] M Sayão, JCS do, P Leite. “Rastreabilidade de Requisitos," Rev. Informática Teórica e Apl. 2005 13(1): 57-86.

[42] V Duc. "Traceability in agile software development projects," University of Gothenburg. 2013.

[43] A Ahmad, MA Ghazali. "Documenting requirements traceability information for small projects," INMIC2007 - 11th IEEE Int. Multitopic Conf. 2007.

[44] W Li, RB Vaughn, H Saiedian. “Pre-Requirements Traceability,” Encycl. Softw. Eng., 61, 2002.

[45] Michaelis. Dicionário Brasileiro da Língua Portuguesa. Barreira, 2020. Accessed on: April 04, 2021. Avaiable at: $<$ https://michaelis.uol.com.br/moderno-portugues/busca/portugues-brasileiro/barreira/>.

[46] Michaelis. Dicionário Brasileiro da Língua Portuguesa. Benefício, 2020. Accessed on: April 04, 2021. Avaiable at: $<$ https://michaelis.uol.com.br/busca?r=0\&f=0\&t=0\&palavra=benefício $>$.

[47] PH da Silva, J Crippa, S Scheer. "BIM 4D no planejamento de obras: detalhamento, benefícios e dificuldades," PARC Pesqui. em Arquitetura e Construção, 10: e019010, 2019,

[48] B Ramesh, M Jarke. “Toward reference models for requirements traceability," IEEE Trans. Softw. Eng. 2001; 27(1): 58-93.

[49] AEK Sahraoui. "Requirements traceability issues: Generic model, methodology and formal basis," Int. J. Inf. Technol. Decis. Mak. 2005; 4(1): 59-80.

[50] I Galvao, A Goknil. "Survey of Traceability Approaches in Model-Driven Engineering," in 11th IEEE International Enterprise Distributed Object Computing Conference. 2008; 313-313.

[51] SMZ Ahmed, C McKnight, C Oppenheim. "A user-centred design and evaluation of IR interfaces," J. Librariansh. Inf. Sci. 2006; 38(3): 157-172.

[52] B Kitchenham. "Procedures for Performing Systematic Reviews," Keele, Uk, Keele Univ. 2004; 33: 1-26.

[53] EC Conforto, DC Amaral, SL da Silva. "Roteiro para revisão bibliográfica sistemática: aplicação no desenvolvimento de produtos e gerenciamento de projetos," in $8^{\circ}$ Congresso Brasileiro de Gestão de Desenvolviemnto de Produto - CNGDP 2011, 2011, 1998; 1-12.

[54] B Ramesh. "Factors influencing requirements traceability practice," Commun. ACM. 1998; 41(12): 37-44.

[55] JN Latta, DJ Oberg. “A conceptual virtual reality model," IEEE Comput. Graph. Appl. 1994; 14(1): 23-29.

[56] M Weber, J Weisbrod. "Requirements engineering in automotive development: Experiences and challenges," IEEE Softw. 2003; 20(1): 16-24.

[57] M Hoffmann, N Kühn, M Weber, M Bittner. "Requirements for requirements management tools," Proc. IEEE Int. Conf. Requir. Eng. 2004; 301-308.

[58] P Arkley, S Riddle. "Overcoming the Traceability benefit problem," Proc. IEEE Int. Conf. Requir. Eng. 2005; 385389.

[59] J Cleland-Huang. "Toward improved traceability of non-functional requirements," Proc. - 3rd ACM Int. Work. Traceability Emerg. Forms Softw. Eng. TEFSE 2005, Held with 20th IEEE/ACM Int. Conf. Autom. Softw. Eng. ASE. 2005; 14-19.

[60] A Egyed, S Biffl, M Heindl, P Grünbacher. "Determining the cost-quality trade-off for automated software traceability," 20th IEEE/ACM Int. Conf. Autom. Softw. Eng. ASE 2005, 360-363.

[61] J Roberts. "Disney, Dewey, and the Death of Experience in Education," Educ. Cult. 2005; 21(2): 12-30.

[62] G Antoniol, B Berenbach, A Eyged, S Ferguson, J Maletic, A Zisman. "Center of Excellence for Traceability- Problem Statements and Grand Challenges," Cent. Excell. Traceability Tech. Rep. 2006; 1-10. 
[63] A De Lucia, F Fasano, R Oliveto. "Traceability management for impact analysis," Proc. 2008 Front. Softw. Maintenance, FoSM November 2008; 21-30.

[64] A Kannenberg, H Saiedian. "Why Software requirements Traceability Remains a Challenge," J. Def. Softw. Eng. CrossTalk J. Def. Softw. Eng. 2009; 14-19.

[65] E Bouillon, P Mäder, I Philippow. "A survey on usage scenarios for requirements traceability in practice," in International Working Conference on Requirements Engineering: Foundation for Software Quality. 2013; 158-173.

[66] M Berkovich, JM Leimeister, A Hoffmann, H Krcmar. "A requirements data model for product service systems," Requir. Eng. 2014; 19(2): 161-186.

[67] AMD Duarte, D Duarte, M Thiry. "TraceBoK: Toward a Software Requirements Traceability Body of Knowledge," Proc. - 2016 IEEE 24th Int. Requir. Eng. Conf. RE. 2016; 236-245.

[68] GO Da Trindade, M Lucena. "Rastreabilidade de requisitos em metodologias ágeis: Um estudo exploratório," SBSI 2016 - 12th Brazilian Symp. Inf. Syst. Inf. Syst. Cloud Comput. Era, Proc. 2016; 478-485.

[69] R Elamin, R Osman. "Implementing traceability repositories as graph databases for software quality improvement," Proc. - 2018 IEEE 18th Int. Conf. Softw. Qual. Reliab. Secur. QRS. 2018; 1: 269-276.

[70] S Jayatilleke, R Lai. “A systematic review of requirements change management," Inf. Softw. Technol. 2018; 93: 163-185.

[71] B Wang, R Peng, Y Li, H Lai, Z Wang. "Requirements traceability technologies and technology transfer decision support: A systematic review," J. Syst. Softw. 2018; 146: 59-79.

[72] R Watkins, M Neal. "Why and how of requirements tracing," IEEE Softw. 1994; 11(4): 104-106.

[73] B Nuseibeh, S Easterbrook. "Requirements engineering: A roadmap," Proc. Conf. Futur. Softw. Eng. ICSE. 2000; 1: 35-46.

[74] R Oberg, L Probasco, M Ericsson. “Applying requirements management with use cases,” Ration. Softw. Corp. 2000; $5(24)$.

[75] S Hansen, N Berente, K Lyytinen. "Requirements in the 21st century: Current practice and emerging trends," Lect. Notes Bus. Inf. Process., 14 LNBIP. 2009; 44-87.

[76] A Espinoza, J Garbajosa. "A study to support agile methods more effectively through traceability," Innov. Syst. Softw. Eng. 2011; 7(1): 53-69.

[77] A Janes, T Remencius, A Sillitti, G Succi. “Managing changes in requirements: an empirical investigation," J. Softw. E Process. 2013; 25(12): 1172-1192.

[78] R Dreves, F Hällmayer, L Haunert, B Sechser, A Rieß. “A method to realize traceability in development processes," J. Softw. E Process. 2016; 28(11): 1011-1019.

[79] A Wibowo, J Davis. "Requirements Traceability Ontology to Support Requirements Management," PervasiveHealth Pervasive Comput. Technol. Healthc. 2020.

[80] K Garmer, J Ylvén, ICM Karlsson. “User participation in requirements elicitation comparing focus group interviews and usability tests for eliciting usability requirements for medical equipment: A case study," Int. J. Ind. Ergon. 2004; 33(2): 85-98.

[81] Project Management Institute (PMI), Um guia do conhecimento em gerenciamento de projetos, 5th ed. Newtown Square, Pennsylvania 19073-3299: GlobalStandard. 2013.

[82] N Nurmuliani, D Zowghi, SP. Williams, "Using Card Sorting Technique to Classify Requirements Change," twelfth IEEE Int. Conf. Requir. Eng. 2004; 240-248.

[83] D Baxter et al., "A framework to integrate design knowledge reuse and requirements management in engineering design," Robot. Comput. Integr. Manuf. 2008; 24(4): 585-593.

[84] J Ward, E Daniel, Benefits Management: Delivering Value from IS \& IT Investments. John Wiley \& Sons Ltd. 2006. 